Владислав Григорович Солонніков (доктор техніч. наук, професор)

Олександр Володимирович Войтко (канд. військ. наук)

Олена Владиславівна Полякова

Національний університет оборони Украӥни імені Івана Черняховського, Київ, Украӥна

\title{
РІВНЯННЯ ПЕРІОДИЧНИХ ПРОЦЕСІВ, ЯКІ ВРАХОВУЮТЬ ОСОБЛИВОСТІ ДИНАМІКИ ЇХ ПРОТІКАННЯ В СИСТЕМАХ УПРАВЛІННЯ ЛІТАЛЬНИХ АПАРАТІВ 3 БОРТОВОЮ ЦИФРОВОЮ ОБЧИСЛЮВАЛЬНОЮ МАШИНОЮ
}

У статті шляхом сумісного використання математичного апарату перетворення Лапласа та його дискретного аналогу (D - перетворення) на основі метода гармонічної лінеаризації отримані рівняння, які описують мимовільні періодичні процеси, щуо виникають в нелінійних безперервно-дискретних системах (БДС) автоматичного управління. Отримані рівняння періодичних процесів враховують специфіку динамічних властивостей нелінійних БДС й приймають різний вигляд в залежності від особливостей структурної схеми досліджуваної системи (від типу нелінійного елементу, кількості місия розташування імпульсних елементів відносно нелінійного елементу). Вони дозволяють досліджувати найпростіші мимовільні періодичні прочеси, а також специфічні для БДС періодичні прочеси, частота яких не пов'язана иілечисельним співвідношенням з частотою замикання імпульсного елемента системи. Це дає можливість більи повно врахувати характер можливих в системі періодичних режимів і підвищити точність визначення їх параметрів.

Ключові слова : гармонічна лінеаризачія, імпульсний елемент, нелінійний елемент, безперервнодискретна система автоматичного управління.

\section{Вступ}

В умовах тимчасової окупації Російською Федерацією території Автономної Республіки Крим та проведення операції об'єднаних сил в окремих районах Донецької та Луганської областей ступінь актуальності проблеми підвищення боєздатності та боєготовності Збройних сил України набуває визначального статусу. Це в повному обсязі стосується і ЗРВ Повітряних Сил Збройних Сил України. Враховуючи очевидну тенденцію випереджувального зростання малопомітних і малоуразливих для зенітних ракетних комплексів (ЗРК) безпілотних літальних апаратів і їх частки в загальному арсеналі засобів повітряного нападу Збройних Сил Російської Федерації, можна зробити висновок про необхідність прийняття дієвих заходів щодо підвищення бойових можливостей ЗРК, що знаходяться на озброєнні наших ЗРВ [1,2].

Постановка проблеми. Потреби військ настійно диктують необхідність підвищення точності, завадозахищеності, адаптивності до умов стрільби і загальної ефективності застосування зенітних керованих ракет (ЗКР).

Кінцевий результат застосування ЗКР проти повітряної цілі залежить від якості функціонування під час польоту к цілі всіх їі основних підсистем. Відповідні експерти вважають, що суттєвих результатів покращення тактико-технічних характеристик (ТTX) ЗКР, а тобто і підвищення ефективності ЗРК в цілому, можна досягнути за рахунок застосування бортових цифрових обчислювальних машин (БЦОМ) у складі іiі бортового обладнання. Використання БЦОМ у складі бортової апаратури ЗКР дозволяє реалізовувати складні алгоритми обробки інформації, значно підвищити надійність, завадо захищеність і точність наведення ракети на ціль. 3 використанням БЦОМ може бути оптимізований i процес управління функціонуванням бойового спорядження ЗКР, а тобто і всім процесом знищення повітряної цілі. На базі БЦОМ можна здійснити комплексну цифрову алгоритмізацію i оптимізацію процесу функціонування бортової апаратури ЗКР i як наслідок - підвищити ефективність застосування ЗРК

Аналіз остатніх досліджень і публікацій.

Включення БЦОМ до складу бортової апаратури ЗКР відкриває широкі перспективи щодо удосконалення ТТХ ракети, однак наявність у складі систем управління БЦОМ може призвести і до деякий негативних явиш. . Наприклад, в таких системах можуть непередбачено виникати неконтрольовані коливальні процеси, які можуть звести нанівець процес наведення ЗКР на ціль. Для запобігання цим явищам треба більш детально досліджувати такі системи.

Комплексний аналіз систем управління ЗКР 3 БЦОМ як об'єкта дослідження дозволяє стверджувати, що вони відносяться до класу нелінійних безперервно-дискретних систем (БДС)

(C) В.Г.Солонніков, О.В. Войтко, О.В. Полякова

Modern Information Technologies in the Sphere of Security and Defence № 3(33)/2018

ISSN2311-7249(Print)/ISSN 2410-7336(Onfine) 
автоматичного управління 3 надзвичайно складними динамічними властивостями.

Динаміка функціонування таких систем описується сукупністю диференційних i різницевих рівнянь, частина 3 яких можуть бути нелінійними або відрізнятися змінними у часі коефіцієнтами. Точні методи рішення таких рівнянь відсутні.

При дослідженні і розрахунку систем управління ЗКР 3 БЦОМ в частотній області доцільно застосовувати одночасно математичний апарат безперервного і дискретного перетворення Лапласа, який дозволяє достатньо повно враховувати особливості протікання процесів в автоматичних системах безперервно-дискретного класу.

Для виявлення умов виникнення мимовільних періодичних режимів в нелінійних безперервнодискретних системах автоматичного управління доцільно використовувати метод гармонічної лінеаризації [3-5]. У зв'язку з цим авторами даної статті у роботі [6] розглянуті особливості проведення гармонічної лінеаризації нелінійного елемента в системах управління літальних апаратів з БЦОМ в контурі управління. Показано, що для цього необхідно у взаємодії розглядати як властивості, що притаманні безперервній частині системи (нелінійність, нестаціонарність, багато режимність і т.п.), так і властивості, що викликані дискретизацією процесів управління за часом i рівнем, яка відбувається в БЦОМ. Доведено, що при проведенні гармонічної лінеаризації нелінійного елемента (НЕ) в БДС необхідно враховувати його розміщення у структурній схемі системи відносно імпульсного елемента (IE) та лінійної частини системи, а також наявність чи відсутність інерційних властивостей у самого НЕ. В залежності від цього для БДС 3 одним нелінійним i одним імпульсним елементом можливі чотири варіанти структурних схем одноконтурних БДС, для кожної 3 яких потрібно застосовувати різні коефіцієнти гармонічної лінеаризації. Отримані математичні залежності для ï розрахунку. Це дає змогу враховувати специфіку динамічних властивостей конкретних нелінійних НДС.

Мета статті. 3 використанням запропонованих коефіцієнтів гармонічної лінеаризації далі планується отримати рівняння, які описують

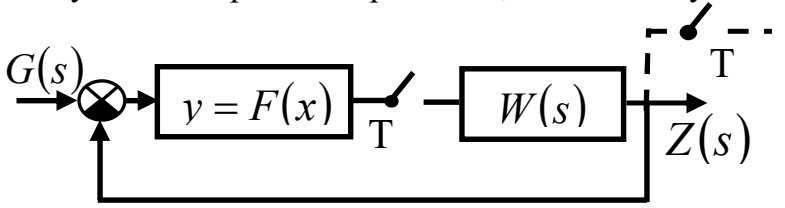

a)

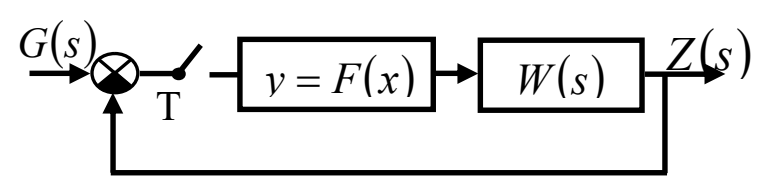

б) мимовільні періодичні процеси, що можуть виникати в нелінійних БДС автоматичного управління.

\section{Виклад основного матеріалу дослідження}

Важливою задачею проектування лінійних БДС автоматичного управління $є$ задача забезпечення у них властивості стійкості. Пояснюється це тим, що тільки після реалізації стійкості системи можна висувати будь-які вимоги до iï працездатності. Для нелінійних БДС автоматичного управління, як i для лінійних, питання стійкості є першочерговим. Однак, якщо для лінійних систем знаходження системи на границі стійкості є дійсно граничним, розглядати яке можна лише в чисто теоретичній постановці питання, то для нелінійних систем стан системи, при якому процеси в ній носять характер сталих періодичних коливань, $\epsilon$ не тільки одним 3 можливих, але часто навіть робочим станом системи. Можливість існування періодичних процесів у нелінійних БДС автоматичного управління $\epsilon$ їхньою внутрішньою властивістю, внаслідок чого виникнення таких процесів можливо як при наявності, так і при відсутності зовнішніх впливів на функціонування системи.

Періодичні процеси в нелінійних БДС по своїй природі споріднені 3 автоколиваннями, що виникають в нелінійних безперервних системах автоматичного управління, однак на їхнє формування суттєво впливає синхронізуюча дія IE системи.

При відшуканні параметрів періодичних процесів у нелінійних безперервних і нелінійних дискретних системах наближеними методами досить хороші результати вдається одержати при використанні частотного методу, заснованого на гармонічній лінеаризації НЕ системи. У зв'язку із цим вивід рівнянь періодичних процесів для нелінійних БДС теж доцільно проводити на базі методу гармонічної лінеаризації. Застосування методу гармонічної лінеаризації до нелінійних БДС, як було показано вище, має істотні особливості. Вони полягають у тому, що залежно від виду структурної схеми системи (рис.1а, б, в, г) гармонічну лінеаризацію НЕ потрібно здійснювати шляхом заміни його коефіцієнтами, що мають різні формульні вирази.

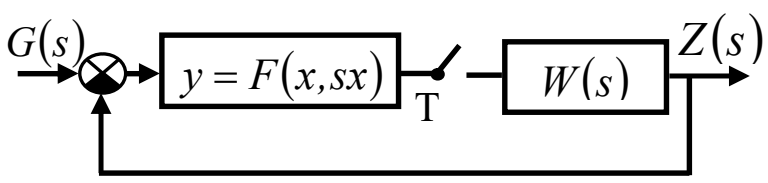

в)

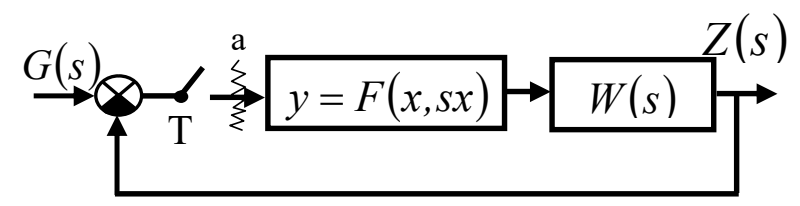

г)

Рис. 1. Можливі варіанти структурних схем одноконтурних БДС із одним імпульсним і одним нелінійним елементом. 
Одержимо рівняння мимовільних періодичних процесів, що виникають у нелінійних БДС, структурні схеми яких аналогічні зображеній на рис.1г. Особливістю розглянутої структурної схеми є дискретність вхідного сигналу НЕ системи і залежність вихідного сигналу НЕ від похідної сигналу, що діє на його вході. Здійснивши заміну НЕ системи відповідним йому еквівалентним комплексним коефіцієнтом передачі [6]

$I(A, j \omega, N, \varphi)=\sqrt{q^{2}(A, \omega, N, \varphi)+q^{\prime 2}(A, \omega, N, \varphi)} e^{j a r c t \frac{q^{\prime}(A, \omega, N, \varphi)}{q(A, \omega, N, \varphi)}}$

i розглядаючи процеси в ній відносно зображень по Лапласу, НЕ і лінійну частину системи можна характеризувати однією передаточною функцією

$$
W(A, s, N, \varphi)=I(A, s, N, \varphi) W(s) . \quad(1)
$$

Передаточна функція $W(A, s, N, \varphi) \quad \epsilon$ добутком коефіцієнта передачі $\mathrm{HE}$ після лінеаризації і передаточної функції лінійної частини системи.

На підставі визначення зворотного $D$ перетворення запишемо вираз для зображення по Лапласу вихідної координати системи

$$
\begin{aligned}
& Z(A, s, N, \varphi)=\int_{0}^{1} Z^{*}(A, s, N, \varphi, \varepsilon) e^{-s T \varepsilon} d \varepsilon= \\
& =\int_{0}^{1} G^{*}(s) \frac{W^{*}(A, s, N, \varphi, \varepsilon)}{1+W^{*}(A, s, N, \varphi)} e^{-s T \varepsilon} d \varepsilon=\frac{W(A, s, N, \varphi)}{1+W^{*}(A, s, N, \varphi)} G^{*}(s)= \\
& =\Phi(A, s, N, \varphi) G^{*}(s) . \\
& \quad 3 \text { (2) витікає, що передаточна функція }
\end{aligned}
$$

замкнутої лінеаризованої БДС, яка обумовлена відношенням перетворення Лапласа вихідної координати системи до дискретного перетворення Лапласа ïi вхідного сигналу, розраховується по формулі

$$
\Phi(A, s, N, \varphi)=\frac{Z(A, s, N, \varphi)}{G^{*}(s)}=\frac{W(A, s, N, \varphi)}{1+W^{*}(A, s, N, \varphi)} .
$$

Вираз (2) можна поставити у відповідність структурній схемі, що зображена на рис. 2а. 3 аналізу цього рисунку витікає, що в результаті проведеного структурного перетворення вдалося винести IE iз замкнутого контуру системи. Тому замкнуту частину структурної схеми (рис. 2б) можна розглядати як безперервну систему, передаточна функція розімкнутого контуру якої має вигляд

$$
W_{1}(A, s, N, \varphi)=\frac{W(A, s, N, \varphi)}{W^{*}(A, s, N, \varphi)-W(A, s, N, \varphi)+1}
$$

Вільні періодичні процеси, які здатні виникнути в замкнутому контурі розглянутої системи, можна характеризувати рівнянням

$$
\frac{W(A, s, N, \varphi)}{W^{*}(A, s, N, \varphi)-W(A, s, N, \varphi)+1}=-1
$$

Враховуючи (1), рівняння (5) можна привести до виду

$$
\{I(A, s, N, \varphi) W(s)\}^{*}=-1 \text {. }
$$

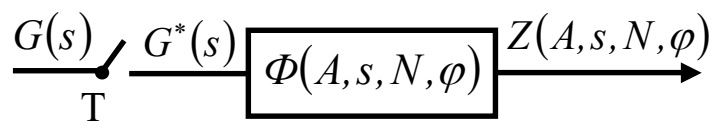

a)

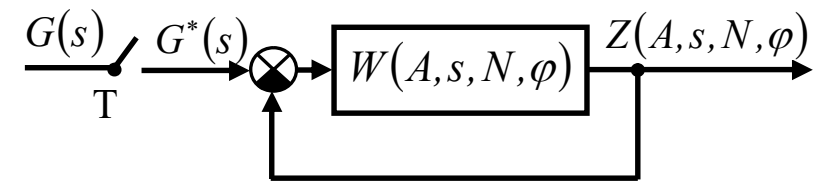

б)

Рис. 2. Еквівалентне представлення структурної схеми системи, зображеної на рис. 2.1,г

Рівняння (6), що визначають параметри мимовільних періодичних рухів у нелінійній БДС зі структурною схемою (рис. 1г) можна одержати i без перетворення вихідної структурної схеми. Дійсно, розімкнувши контур системи в точці “a” i скориставшись визначеннями передаточних функцій безперервної і дискретної частин системи автоматичного управління, вираз для сигналу на виході IE можна записати у вигляді

$$
X^{*}(s)=G^{*}(s)-X_{1}^{*}(s)\{I(A, s, N, \varphi) W(s)\}^{*}
$$

Замкнувши контур у точці розриву, одержимо $X^{*}(s)=X_{1}^{*}(s)$ i, отже,

$$
X^{*}(s)=\frac{G^{*}(s)}{1+\{I(A, s, N, \varphi) W(s)\}^{*}}
$$

Вираз для визначення сигналу на виході системи відповідно буде мати вигляд

$$
Z(A, s, N, \varphi)=\frac{I(A, s, N, \varphi) W(s)}{1+\{I(A, s, N, \varphi) W(s)\}^{*}} G^{*}(s)=\Phi(A, s, N, \varphi) G^{*}(s),
$$

де $\Phi(A, s, N, \varphi)$ - передаточна функція замкнутої лінеаризованої БДС автоматичного управління.

При відшуканні мимовільних періодичних процесів передбачається відсутність вхідного сигналу системи, тому

$$
\{I(A, s, N, \varphi) W(s)\}^{*}+1=0 .
$$

Рівняння (7) визначає умови перебування лінеаризованої нелінійної БДС на границі стійкості, повністю збігається з рівнянням (6) i, отже, своїм рішенням визначає параметри можливих у системі мимовільних періодичних процесів. Оскільки обидві функції, що стоять під знаком операції дискретного перетворення Лапласа, залежать від частоти, то умова (7) на підставі теореми $D$-перетворення про множення зображень двох функцій можна переписати у вигляді

$$
\int_{0}^{1} I^{*}(A, j \omega, N, \varphi, \varepsilon-\lambda) W^{*}(j \omega, \lambda) d \lambda=-1
$$

У виразах (7) і (8):

$W^{*}(j \omega, \lambda), W^{*}(j \omega, \varepsilon-\lambda)-$ зміщені дискретні частотні характеристики лінійної частини нелінійної БДС;

$$
I^{*}(A, j \omega, N, \lambda), I^{*}(A, j \omega, N, \varphi, \varepsilon-\lambda)
$$


зміщені дискретні амплітудно-фазові частотні характеристики гармонічно лінеаризованого $\mathrm{HE}$ системи;

$\varepsilon$ і $\lambda$ - дійсні числа, що змінюються в межах від 0 до1.

Прийнято вважати, що частота періодичних режимів, що виникають у нелінійних імпульсних системах, жорстко пов'язана із частотою замикання IE і перебуває 3 нею в цілочисловому співвідношенні [4]. Проте автори деяких робіт, присвячених дослідженню “автоколивань” у нелінійних імпульсних системах, не заперечують можливість виникнення в системах даного класу складних періодичних процесів, періоди повторення яких не $\epsilon$ кратними періоду квантування IE системи [7]. Викладений підхід до визначення періодичних процесів також підтверджує теоретичну можливість виникнення таких мимовільних режимів роботи системи. Про це свідчать рівняння (7) i (8). Рівняння періодичних процесів у записі (7) і (8) охоплюють все різноманіття близьких до гармонійних “автоколивальних" процесів, здатних виникнути в нелінійних БДС із розглянутою структурною схемою. Однак, враховуючи великі труднощі практичного використання рівнянь (7) i (8) для розрахунку параметрів періодичних процесів, що свідчать про прояв нелінійними імпульсними системами резонансних властивостей на частотах, кратних частоті замикання IE, перевірку виконання умов (7), (8) варто проводити лише для частот $\omega=\frac{\pi}{T}$, при $N=1,2,3, \ldots$. У цьому випадку за рахунок рівності нулю параметрів $\varepsilon$ i $\lambda$ рівняння періодичних режимів істотно спрощуються і приймають вигляд

$$
W^{*}\left(j \frac{\pi}{N}\right)=-\frac{1}{I^{*}\left(A, j \frac{\pi}{N}, N, \varphi\right)} .
$$

Рівняння (9) на відміну від (7) i (8) характеризує лише прості мимовільні періодичні режими, період повторення яких кратний періоду замикання IE системи $\left(T_{1}=2 T \cdot N\right)$. Проте для визначення параметрів цих режимів рівняння (9) дозволяє запропонувати порівняно простий графоаналітичний спосіб. Для виводу рівнянь періодичних процесів нелінійних БДС, у структурних схемах яких імпульсний і нелінійний елементи розділені лінійною інерційною ланкою, а НЕ описується рівнянням $y=F(x, s x)$, гармонічну лінеаризацію НЕ потрібно здійснювати шляхом заміни його еквівалентним комплексним коефіцієнтом передачі, що розраховується по формулі

$$
W(A, j \omega)=\sqrt{q^{2}(A, \omega)+q^{\prime 2}(A, \omega)} e^{j a r c t g \frac{q^{\prime}(A, \omega)}{q(A, \omega)}}
$$

Шляхом міркувань, аналогічних раніше наведеним, можна показати, що рівняння періодичних процесів для нелінійної БДС зі структурною схемою (рис. 1в) має вигляд

$$
\{W(A, s) W(s)\}^{*}=-1 .
$$

Розкриваючи символ операції-перетворення, рівняння (10) можна представити у вигляді кожної 3 наступних записів

$$
\begin{gathered}
\int_{0}^{1} W^{*}(A, j \omega, \varepsilon-\lambda) W^{*}(j \omega, \varepsilon) d \varepsilon=-1 ; \\
\int_{0}^{1} W^{*}(A, j \omega, \lambda) W^{*}(j \omega, \varepsilon-\lambda) d \varepsilon=-1 .
\end{gathered}
$$

Відповідно до цього рівняння для визначення періодичних процесів 3 періодом повторення, кратним періоду замикання IE нелінійної БДС із

розглянутою структурною схемою, буде мати вигляд

$$
W^{*}\left(j \frac{\pi}{N}\right)=\frac{1}{W^{*}\left(A, j \frac{\pi}{N}\right)} .
$$

Наводити окремо вивід рівнянь періодичних процесів для нелінійних БДС зі структурними схемами (рис. 1а, б) теж немає необхідності, тому що ці структурні схеми відрізняються від структурних схем (рис.1 в, г) лише властивостями $\mathrm{HE}$, що входить до їх складу. У зв'язку із цим рівняння періодичних процесів для автоматичних систем зі структурними схемами (рис. 1а, б) будуть відрізнятися від рівнянь (6), (7) тільки виразами для еквівалентних комплексних коефіцієнтів передачі НЕ.

$$
\begin{aligned}
& \left\{I^{*}(A, N, \varphi) W(j \omega)\right\}^{*}=-1 \\
& \left\{W^{*}(A) W(j \omega)\right\}^{*}=-1
\end{aligned}
$$

На підставі теореми-перетворення про множення зображень і теореми лінійності рівняння (14), (15) для визначення найбільш імовірних мимовільних періодичних процесів треба застосовувати у вигляді

$$
\begin{aligned}
& W^{*}\left(j \frac{\pi}{N}\right)=-\frac{1}{I^{*}(A, N, \varphi)} ; \\
& W^{*}\left(j \frac{\pi}{N}\right)=-\frac{1}{W(A)} \cdot
\end{aligned}
$$

Якщо нелінійна БДС автоматичного управління містить декілька IE, наприклад два, то можна показати, що залежно від місця розташування імпульсних елементів у структурній схемі системи (рис. 3a, б, в, г) і властивостей їі НЕ рівняння періодичних режимів будуть мати вигляд

$$
\begin{aligned}
& \left\{I(A, j \omega, N, \varphi) W_{1}^{*}(j \omega) W_{2}(j \omega)\right\}^{*}=-1 ; \\
& \left\{W(A, j \omega) W_{1}^{*}(j \omega) W_{2}(j \omega)\right\}^{*}=-1 ; \\
& \left\{I^{*}(A, N, \varphi) W_{1}^{*}(j \omega) W_{2}(j \omega)\right\}^{*}=-1 ; \\
& \left\{W(A) W_{1}^{*}(j \omega) W_{2}(j \omega)\right\}^{*}=-1 .
\end{aligned}
$$




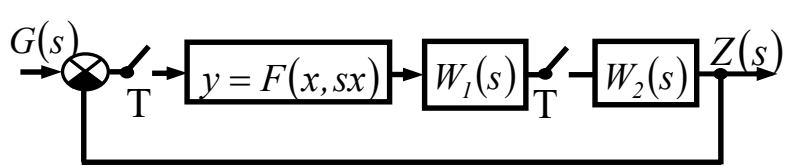

a)

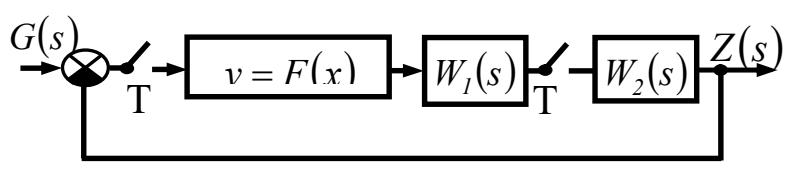

B)

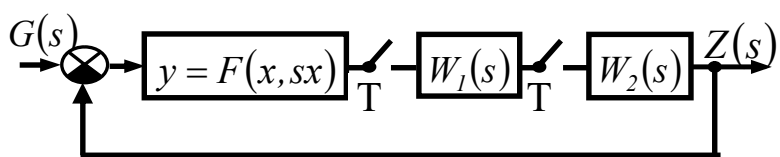

б)

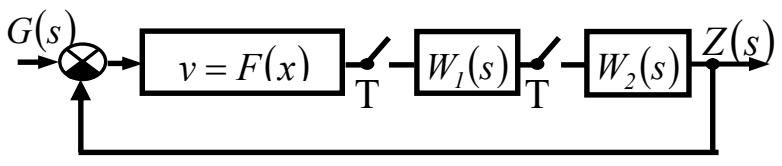

г)

\section{Рис. 3. Структурні схеми нелінійних НДС з двома ИС}

Для цілей визначення параметрів найпростіших мимовільних періодичних режимів рівняння (18) - (21) можна застосовувати у вигляді

$W_{1}^{*}\left(j \frac{\pi}{N}\right) W_{2}^{*}\left(j \frac{\pi}{N}\right)=-\frac{1}{I^{*}\left(A, j \frac{\pi}{N}, \varphi\right)}$

$W_{1}^{*}\left(j \frac{\pi}{N}\right) W_{2}^{*}\left(j \frac{\pi}{N}\right)=-\frac{1}{W^{*}(A, j \omega)} ;$

$W_{1}^{*}\left(j \frac{\pi}{N}\right) W_{2}^{*}\left(j \frac{\pi}{N}\right)=-\frac{1}{I^{*}(A, N, \varphi)} ;$

$W_{1}^{*}\left(j \frac{\pi}{N}\right) W_{2}^{*}\left(j \frac{\pi}{N}\right)=-\frac{1}{W(A)}$.

Аналіз рівнянь (6), (10), (14), (15) і (22) - (25) показує, що в кожному з них під знаком операції $D$-перетворення стоїть вираз передаточної функції розімкнутої лінеаризованої БДС, що одержується iз замкнутої розривом ланцюга одиничного зворотного зв'язку. Отже, можна стверджувати, що спільною частотною умовою виникнення в нелінійній БДС періодичних процесів $є$ рівність від’ємній одиниці $D$-перетворення від передаточної функції розімкнутої гармонічно лінеаризованої системи.

Відмінність рівнянь періодичних процесів нелінійних БДС із різним взаємним розташуванням нелінійного i імпульсного елементів в їхніх структурних схемах полягає у використанні різних коефіцієнтів гармонічної лінеаризації НЕ. Це дозволяє більш повно врахувати характер можливих у системі періодичних режимів і підвищити точність визначення їх параметрів.

\section{Висновки й перспективи подальших досліджень}

Виходячи 3 викладеного, можна зробити наступні висновки:

При проведенні гармонічної лінеаризації НЕ в

\section{Jimepamypa}

1. Протидія безпілотним авіаційним комплексам: Методичний посібник. К.: НУОУ, 2016.-28 с. 2. Застосування БпЛА в конфліктах сучасності / [Ю.К.Зіатдінов, М.В.Куклінський, С.П.Мосов, А.Л.Фещенко та ін.]; під ред. С.П.Мосова. - К.:2013. - 248 с. 3. Цыпкин Я.3. Теория
БДС необхідно враховувати його розміщення у структурній схемі системи відносно IE та лінійної частини системи, а також наявність чи відсутність інерційних властивостей у самого НЕ.

Для БДС 3 одним нелінійним і одним імпульсним елементом можливі чотири варіанти структурних схем одноконтурних БДС, для кожної 3 яких потрібно застосовувати різні коефіцієнти гармонічної лінеаризації НЕ. Це дає змогу враховувати специфіку динамічних властивостей конкретних нелінійних БДС.

3 використанням запропонованих в [6] коефіцієнтів гармонічної лінеаризації НЕ отримані рівняння, які описують мимовільні періодичні процеси, що можуть виникати в нелінійних БДС автоматичного управління.

При зміні структурної схеми БДС за рахунок введення додаткових IE рівняння періодичних процесів змінюються. Отже, перевагою запропонованих рівнянь $є$ не тільки придатність їх для дослідження мимовільних періодичних процесів у будь-якій нелінійній БДС автоматичного управління, але й можливість врахування 3 їхньою допомогою особливостей характеру виникаючих процесів у кожній конкретній схемі нелінійної БДС залежно від кількості IE i взаємного їх розташування в структурній схемі системи.

В подальшому для практичного дослідження періодичних процесів в нелінійних БДС планується розробити методику, яка дозволить вирішувати це завдання графо-аналітичним методом 3 використанням логарифмічних частотних характеристик елементів структурної схеми системи або чисельними методами розрахунку на ПЕОМ. Методика буде враховувати особливості динаміки БДС, значно полегшить сам процес прогнозування можливості виникнення в системі періодичних процесів і дозволить визначати параметри цих процесів 3 достатньою для практики інженерних розрахунків точністю.

линейных импульсных систем. - М.:Физматгиз, 1963.- 968 с. 4. Ту Ю.Т. Цифровые и импульсные системы автоматическогоуправления.-М Машиностроение, 1964.- 793 с. 5. Кузин Л.Т. Расчет и проектирование дискретных систем управления.- М.: Матгиз, 1963.- 683 с. 6. Солонніков В.Г., Войтко О.В., Полякова О.В. Особливості проведення 
гармонічної лінеарізації нелінійного елемента в системах управління літальних апаратів 3 бортовою цифровою обчислювальною машиною / В.Г.Солонніков, О.В.Войтко, О.В.Полякова // Науковий журнал "Сучасні інформаційні технології у сфері безпеки та оборони”. -
К.: НУОУ ім. Івана Черняховського. - № 2(32), 2018. С. 65-70. 7. Черкашин Г.М., Бахшалісв А.Ш., Рюмшин М.O. Розрахунок безперервно-дискретних систем частотним методом.- К.: Техніка, 1992.- 275 с.

\title{
УРАВНЕНИЯ ПЕРИОДИЧЕСКИХ ПРОЦЕССОВ, УЧИТЫВАЮЩИЕ ОСОБЕННОСТИ ДИНАМИКИ ИХ ПРОТЕКАНИЯ В СИСТЕМАХ УПРАВЛЕНИЯ ЛЕТАТЕЛЬНЫХ АППАРАТОВ С БОРТОВОЙ ЦИФРОВОЙ ВЫЧИСЛИТЕЛЬНОЙ МАШИНОЙ
}

\author{
Владислав Григорьевич Солонников (доктор техн. наук, профессор) \\ Александр Владимирович Войтко (канд. воен. наук) \\ Елена Владиславовна Полякова
}

Национальный университет обороны Украины имени Ивана Черняховского, Киев, Украина

В статье путем совместного применения математического аппарата преобразования Лапласа и его дискретного аналога (D - преобразования) на основе метода гармонической линеаризации получень уравнения, описывающие свободные периодические прочессы, которые возникают в нелинейных непрерывно-дискретных системах (НДС) автоматического управления. Полученные уравнения периодических процессов учитывают специфику динамических свойств нелинейных НДС и принимают различный вид в зависимости от особенностей структурной схемы исследуемой системь (от типа нелинейного элемента, количества и места расположения импульсных элементов относительно нелинейного элемента). Они позволяют исследовать простейшие свободные периодические процессы, а также специфические для НДС периодические процессы, частота которых не связана целочисленным соотношением с частотой замыкания импульсного элемента системы. Это дает возможность более полно учитывать характер возможных в системе периодических режимов и повысить точность определения их параметров.

Ключевые слова: гармоническая линеаризация, импульсный элемент, нелинейный элемент, система автоматического управления.

\section{EQUATIONS OF PERIODIC PROSESSES WHICH COUNT SPECIFICS OF DYNAMICS OF ITS EVOLVING IN CONTROL SYSTEMS OF AERIAL VEHICLES WITH THE DIGITAL COMPUTER ONBOARD}

\author{
Vladislav G. Solonnikov (Doctor of Technical Sciences, Professor) \\ Alexander V. Voitko (Candidate of Military Sciences) \\ Elena V. Polyakova
}

\section{National Defence University of Ukraine named after Ivan Cherniakhovsky}

In the article by means of the combined use of the mathematical apparatus of the Laplace transform and its discrete analogue ( $D$ - transform) on the basis of the method of harmonic linearization, we obtain the equations that describe spontaneous periodic processes occurring in nonlinear continuous discrete systems (CDS) of automatic control. The obtained equations of periodic processes take into account the specifics of the dynamic properties of nonlinear CDS and take a different form depending on the features of the structural scheme of the system under study (from the type of nonlinear element, the quantity and location of the pulsed elements relative to the nonlinear element). They allow us to investigate the simplest spontaneous periodic processes, as well as periodic processes specific to the CDS, the frequency of which is not related to the integral relation with the frequency of the switching of the pulse element of the system. This makes it possible to more fully take into account the kind of possible periodic modes in the system and improve the accuracy of their parameters.

Keywords: harmonic linearization, pulsed element, nonlinear element, uninterrupted discrete system of automatic management.

\section{References}

1. Protédia without a lot of aviatsiy complexes: A methodical student. K $\therefore$ NOUU, 2016.-28 p. $\mathbf{2}$. Zastosuvannya UAVs in the context of conflicts/[Yu.K.Ziatdinov, M.V. Kuklinsky, S.P.Mosov, A.L. Feshchenko and I.]; under ed. S.P.Mosov. - K.: 2013. 248 s. 3. Tsypkin Ya.Z. Theory of linear impulse systems. M.: Fizmatgiz, 1963.- 968 p. 4. Tu Yu.T. Digital and pulse systems of automatic control. -M Mashinostroenie, 1964.793 p. 5. Kuzin, L.T. Calculation and design of discrete control systems. - M .: Matgiz, 1963.- 683 p. 6. Solonnikov V.G., Voytko O.V., Polyakova O.V. (2018), Features of harmonic linearization of nonlinear element in control systems of aerial vehicles with the digital computer onboard, Modern information technologies in the sphere of security and defence, No. 2(32), pp. 65-70. 7. Cherkashin G.M., Bakhshaliyev A.Sh., Ryumshin M.O. Rosrahunok noncontinuous-discrete systems by the frequency method .- K .: Tehnika, 1992.- 275 p. 